\title{
Evaluation of glassy frits as micronutrient fertilizers II. Manganese frits
}

\author{
Ch. H. Henkens and K. W. Smilde \\ Institute for Soil Fertility, van Hallstraat 3, Groningen, The Netherlands
}

Received 24 May, 1966

\section{Summary}

In pot and field experiments manganese sulphate and manganese frits - FTE $\mathrm{Z} 4$ (13\% Mn), HZ $1(15.9 \% \mathrm{Mn}), \mathrm{HZ} 17(21 \% \mathrm{Mn})$ - increased reducible soil manganese, the effect lasting for as least $11 / 2-2$ years. The importance of reducible soil manganese values should not be over-estimated however. As a matter of fact, in some cases there is no clear-cut relationship between these levels and occurrence of manganese deficiency (compare p. 29). Pasture manganese content increased more than four-fold in the first cut following application of $400 \mathrm{~kg}$ of manganese sulphate per hectare, but sharply decreased in later cuts. In the year after application the manganese content was only slightly above its original value. With lower applications of manganese sulphate the effect was smaller and lasted for shorter periods. Manganese frit $\mathrm{HZ} 17$ at $400 \mathrm{~kg}$ per hectare did not affect pasture manganese. In peas both soil $(400 \mathrm{~kg} / \mathrm{ha})$ and foliar applied manganese sulphate resulted in a better control of marsh spot than frit $\mathrm{HZ} 1$ at $800 \mathrm{~kg} / \mathrm{ha}$. The best control was obtained by spraying twice, i.e. in the middle and at the end of the blooming period. In sugar beets soil dressings of manganese sulphate and frits $(\mathrm{HZ} \mathrm{1,} \mathrm{HZ} \mathrm{17)} \mathrm{increased} \mathrm{yield,} \mathrm{sugar} \mathrm{pro-}$ duction and leaf manganese, and decreased incidence of manganese deficiency, all fertilizers being equally effective. With increasing quantities of fertilizer $(100-400 \mathrm{~kg}$ of manganese sulphate, $179-714 \mathrm{~kg}$ of $\mathrm{HZ} 1,86-343 \mathrm{~kg}$ of $\mathrm{HZ} \mathrm{17)} \mathrm{there} \mathrm{was} \mathrm{no}$ significant increase in yield and sugar production, whereas leaf manganese and incidence of manganese deficiency only responded to the higher levels of supply. Spraying proved somewhat less effective than soil application. With none of the treatments manganese deficiency could be controlled during the entire growing period. The percentage of manganese deficient plants was negatively related to both leaf and reducible soil manganese, but no close relationship between manganese deficiency and yield was found. Soil applied manganese fertilizer neither controlled grey speck nor increased yield in oats, succeeding the sugar beet crop. Spraying the oat crop, however, both controlled the deficiency disease and increased yield.

\section{Introduction}

In a previous article (Henkens and Smilde, 1966) an evaluation of copper and molybdenum containing glassy frits was given. It was shown that there is at present no need for copper frits in The Netherlands as deficiencies are better and more easily controlled by the fertilizers commonly in use. Molybdenum frits may, however, be 
useful in agricultural practice, but feasible chemical methods to characterize these products should be available.

Manganese deficiency presents a more complicated problem in The Netherlands than either copper or molybdenum deficiency. Apart from its incidence on diluvial sandy soils where it is easily controllable by avoiding overliming, manganese deficiency frequently occurs on calcareous marine sandy clay soils of high $\mathrm{pH}$ (de Groot, 1957; Henkens, 1958). Soil applications of manganese sulphate are generally of little use under these conditions as manganese is quickly rendered unavailable, and spraying has to be resorted to. The latter method is laborious (Henkens, 1962; Henkens and Jongman, 1965), as more than one treatment is needed during the growing season, and also requires skill to avoid damage (leaf scorching). Moreover, with some crops the results are variable (Henkens, 1958). For these reasons Henkens (1959) attempted to correct manganese deficiency on marine soils by application of large quantities of manganese sulphate $(400-600 \mathrm{~kg} / \mathrm{ha})$. In pot experiments with barley it was found possible to raise the soil manganese status to a level sufficiently high to prevent manganese deficiency. Similar results were obtained under field conditions with potatoes and beets (Henkens, 1962). According to de Groot (1957) for marine sandy clay soils with less than $2 \frac{1}{2} \%$ organic matter, a level of $60-70$ p.p.m. of reducible manganese 1 is in most cases sufficient to prevent manganese deficiency. On soils richer in organic matter manganese deficiency may occur at levels up to 100 p.p.m. of reducible manganese or more. The costs involved in applying such large quantities of manganese sulphate as a soil dressing are prohibitive unless there is a residual effect of at least four to five years (Henkens, 1959, 1962). With these problems in mind it was thought convenient to test slowly soluble manganese containing glassy frits, particularly under field conditions.

\section{Materials and methods}

As pointed out by Middelburg and van Baren (1965) manganese frits for agricultural use can be characterized by their hardness, coarseness (particle size) and manganese content. These authors expressed the hardness as the ' $b$-value' which is a measure for the rate at which manganese is released from its silica carrier (see also Oosting, 1964). In the present experiments FTE $Z$ 4, a soft frit ( $b$-value 2.40 ) containing $15 \%$ $\mathrm{Mn}, \mathrm{HZ} 1$, a harder frit ( $b$-value 0.58 ) with $12.5 \% \mathrm{Mn}$, and $\mathrm{HZ} \mathrm{17}$, a soft frit $(b$-value ca. 10) with $26 \% \mathrm{Mn}$ were used.

\section{Pot experiments}

The response of oats to frit FTE $\mathrm{Z} 4$ and $\mathrm{MnSO}_{4} \cdot 4 \mathrm{H}_{2} \mathrm{O}(24.7 \% \mathrm{Mn})$ was studied in a pot experiment in 1958. The following treatments were given: $0,236,471,942$, $1884 \mathrm{mg}$ of $\mathrm{MnSO}_{4} .4 \mathrm{H}_{2} \mathrm{O} ; 387,774,1549,3097 \mathrm{mg}$ of FTE $\mathrm{Z} 4$ per pot, i.e. 0 , $58.1,116.1,232.3$ and $464.5 \mathrm{mg}$ of $\mathrm{Mn}$ per pot, respectively, which is equivalent to $0,18.5,37.0,74.0$ and $148.0 \mathrm{~kg}$ of $\mathrm{Mn}$ per hectare. Later analyses showed that FTE $\mathrm{Z} 4$ contained only $13 \% \mathrm{Mn}$ and, as a result, the frit quantities have been somewhat too low as compared with the manganese sulphate dressings. Mitscherlich pots were used and the experimental conditions were similar to those described for

1 Extraction of soil with $1 \mathrm{~N}$ ammoniumacetate $+0.2 \%$ hydroquinone at pH 7 (1:20 ratio) (Leeper, 1947). 
the pot experiments with copper frits in the first part of this paper. Oat plants were grown in a soil from the Wieringermeer polder low in reducible manganese $(35$ p.p.m.), with $6.1 \% \mathrm{CaCO}_{3}, 7 \%$ silt + clay $(<16 \mu), 1.8 \%$ organic matter and $\mathrm{pH}(\mathrm{KCl}) 7.6$.

\section{Field experiments}

In 1959 two field experiments, Z 2159 and Z 2160, were laid down on pasture in the province of Zeeland to investigate if the manganese content of grass can be raised by application of various manganese fertilizers. $\mathrm{Z} 2159$ was on a calcareous soil $\left(12.9 \% \mathrm{CaCO}_{3}\right)$, with $14 \%$ ' $<16 \mu$ ', $5.7 \%$ organic matter, 135 p.p.m. of reducible manganese and $\mathrm{pH}(\mathrm{KCl}) 7.4$. $\mathrm{Z} 2160$ was on a soil with $0.6 \% \mathrm{CaCO}_{3}, 33 \%$ ' $<16 \mu$ ', $9.1 \%$ organic matter, 31 p.p.m. of reducible manganese and $\mathrm{pH}(\mathrm{KCl})$ 6.6. The basic fertilizer dressings were supplied by the farmers, i.e. $150-200 \mathrm{~kg}$ of $\mathrm{N}$ (as ammonium nitrate limestone and calcium nitrate) given during spring and summer, and $50-80 \mathrm{~kg}$ of $\mathrm{P}_{2} \mathrm{O}_{5}$ per hectare (as superphosphate) applied at once in early spring. The treatments in each experiment were as follows (expressed on a hectare basis): 0, 100, $200,400 \mathrm{~kg}$ of $\mathrm{MnSO}_{4} .4 \mathrm{H}_{2} \mathrm{O}$, and $400 \mathrm{~kg}$ of $\mathrm{HZ} 17$ frit, applied in early spring. A Youdon square design with four replications was used, the area of each of the 20 plots being $5 \times 10$ square metres. Each experiment was continued for three years. In 1960 and 1961 the usual nitrogen and phosphate dressings were given again. Moreover, in 1960 the variable manganese treatments were repeated in half of the replications of each experiment. Samples were taken each year from two to three grass cuts on all plots, just before allowing cattle to graze on them. A wire-netting cage was placed on top of the sampling sites to avoid contamination by droppings. In december, 1960, soil samples were taken in experiment Z 2159 for analysis of reducible manganese.

Two more experiments, IB 454 and IB 656, were laid down on arable land in the Wieringermeer polder in 1959 and 1961 respectively.

IB 454 was located on a loamy sand soil $\left(3 \%\right.$ ' $<16 \mu$ ') with $1.6 \% \mathrm{CaCO}_{3}, 0.3 \%$ organic matter, 30 p.p.m. of reducible $\mathrm{Mn}$ and $\mathrm{pH}(\mathrm{KCl}) 7.5$. Peas were grown as test crop. The treatments, expressed on a hectare basis, were as follows: $0(a), 400 \mathrm{~kg}$ of $\mathrm{MnSO}_{4} .5 \mathrm{H}_{2} \mathrm{O}(b)$, as $(b)+15 \mathrm{~kg}$ of $\mathrm{MnSO}_{4} .5 \mathrm{H}_{2} \mathrm{O}$, applied by spraying with a $11 / 2 \%$ solution in the middle of the blooming period $(c)$, as $(c)$ without soil applied $\mathrm{MnSO}_{4}(d)$, as $(d)+$ another spray at the end of the blooming period $(e), 800 \mathrm{~kg}$ of $\mathrm{HZ} 1$ frit $(f)$. The design was a Latin square with six replications and plots of $7 \times 7$ square metres. Straw and seed yield and the percentage of seeds affected by marsh spot were determined when the crop was harvested. Results were analysed statistically according to the usual Cochran and Cox methods and the Duncan test was applied to verify the significance of the differences between the treatments.

IB 656 was laid down on a sandy loam $\left(15.9 \%\right.$ ' $<16 \mu$ ') with $4.2 \% \mathrm{CaCO}_{3}, 2.6 \%$ organic matter, 25 p.p.m. of reducible $\mathrm{Mn}$ and $\mathrm{pH}(\mathrm{KCl})$ 7.6. Sugar beets were grown as test crop. As in IB 454, a basic fertilizer dressing was given by the farmer. The variable treatments included (on a hectare basis) : $0,100,200,400 \mathrm{~kg}$ of $\mathrm{MnSO}_{4} \cdot 5 \mathrm{H}_{2} \mathrm{O}$ $(22.8 \% \mathrm{Mn}) ; 178.6,357.1,714.3 \mathrm{~kg}$ of $\mathrm{HZ} 1 \mathrm{frit} ; 85.8,171.4,342.9 \mathrm{~kg}$ of $\mathrm{HZ} 17$ frit, each fertilizer supplying 22.3, 44.6 and $89.2 \mathrm{~kg}$ of $\mathrm{Mn}$ per hectare, respectively. The last treatment comprised spraying (as in experiment IB 454) which was carried out when manganese deficiency became manifest (first week of June) and was repeated when deficiency symptoms reappeared. Unfortunately, the manganese contents of $\mathrm{HZ} 1$ and $\mathrm{HZ} 17$ as stated by the supplier proved erroneous; later analyses showed that these products contained 15.9 and $21.0 \% \mathrm{Mn}$, respectively. 
As a result, the quantities of manganese given per hectare have been different for the different fertilizers. The design of the experiment was four randomized blocks of twelve plots of $7 \times 7$ square metres, the untreated controls occurring twice in each block. By the time the soil was fully covered by the foliage (10th July) leaf samples were taken, using the first mature leaf from the heart. Symptom survey was carried out on 5th September and 12th October. Yield of beets and foliage and sugar production were determined when the crop was harvested (25th October). Soil samples for analysis of reducible manganese were taken after harvesting.

The experiment was continued for another year to study the residual effect of manganese fertilizers on oats. The crop was sprayed when grey speck symptoms appeared (1st of June). Leaf samples were taken prior to spraying; the crop had then attained a height of $20 \mathrm{~cm}$. Grain and straw yield and average grain weight were determined when the crop was harvested. Soil samples were then taken for analysis of reducible manganese.

\section{Results and discussion}

\section{Pot experiments}

No grey speck symptoms were observed in the pot experiments and yield of oats was not significantly influenced by any treatment. Manganese content of straw increased from 22 to 34 p.p.m. and that of grain from 35 to 44 p.p.m. at the highest level of manganese sulphate; FTE Z 4 had no effect however. Higher applications of frit might have affected the manganese content of straw and grain (cf. Middelburg and van Baren, 1965). Application of $148 \mathrm{~kg}$ of manganese per hectare as either $\mathrm{MnSO}_{4} .4 \mathrm{H}_{2} \mathrm{O}$ or FTE $\mathrm{Z} 4$ increased reducible soil manganese from 35 to $75-80$ p.p.m. This difference still existed $11 / 2$ year after application of the fertilizers. Apparently, under the conditions of this pot experiment 35 p.p.m. of reducible manganese was sufficient to prevent manganese deficiency.

Field experiments

The results of experiment $\mathrm{Z} 2159$ and $\mathrm{Z} 2160$ on pasture are presented in Table 1 and 2, respectively. Application of manganese sulphate caused a substantial increase

Table 1 Effect of different manganese fertilizers on pasture manganese (p.p.m. on dry matter) as determined in different cuts in experiment $Z$ 2159; each figure represents the mean of four plots

\begin{tabular}{|c|c|c|c|c|c|c|c|c|c|c|}
\hline & \multicolumn{2}{|c|}{1959 cuts } & \multicolumn{4}{|c|}{1960 cuts } & \multicolumn{4}{|c|}{$1961 \mathrm{cuts}_{\mathrm{s}}$} \\
\hline & May 4 & July 29 & June & 13 & $S e_{1}$ & .7 & $\mathrm{Ma}$ & 15 & $A u g$ & 7 \\
\hline & & & $A^{1}$ & $B$ & $A$ & $B$ & $A$ & $B$ & $A$ & $B$ \\
\hline $0 \mathrm{~kg} \mathrm{MnSO}_{4} \cdot 4 \mathrm{H}_{2} \mathrm{O}$ per ha & 41 & 26 & 28 & 31 & 43 & 44 & 58 & 60 & 28 & 28 \\
\hline $100 \mathrm{~kg} \quad$, & 91 & 33 & 40 & 43 & 62 & 73 & 61 & 71 & 31 & 33 \\
\hline $200 \mathrm{~kg}$ & 161 & 31 & 44 & 49 & 55 & 75 & 72 & 74 & 32 & 38 \\
\hline $400 \mathrm{~kg} \quad$, & 198 & 43 & 49 & 88 & 81 & 98 & 77 & 95 & 33 & 45 \\
\hline $400 \mathrm{~kg} \mathrm{HZ} 17$ per ha & 45 & 26 & 33 & 33 & 42 & 51 & 67 & 73 & 32 & 36 \\
\hline
\end{tabular}

$1 \quad A=$ application of fertilizers in 1959 only; $B=$ application of fertilizers in 1959 and 1960 
in manganese content of the sward, the effect being largest in the first cut whereas it sharply decreased in later cuts. Contamination of the samples can be largely excluded as the manganese frit $\mathrm{HZ} 17$ had no influence on pasture manganese content. The residual effect in the year after treatment was small and mainly occured at the highest rate of manganese sulphate. Manganese frit $\mathrm{HZ} \mathrm{17,} \mathrm{however,} \mathrm{did} \mathrm{not} \mathrm{signi-}$ ficantly affect pasture manganese, not even if applied twice at the rate of $400 \mathrm{~kg} / \mathrm{ha}$. IJ. Tj. Bakker (personal communication, 1959) and J. Tesink (personal communication, 1962) also found manganese frit to be ineffective in increasing pasture manganese. It is interesting to note, however, that the manganese frit did increase reducible soil manganese, as was observed in experiment $Z$ 2159. Soil analysis, 21 months after application of the different fertilizers, gave the following results: 135 (control), 200 (100 kg $\left.\mathrm{MnSO}_{4}\right), 306(200 \mathrm{~kg} \mathrm{MnSO}$ ), $371(400 \mathrm{~kg} \mathrm{MnSO}$ ) and 256 (400 kg Mn frit) p.p.m. of reducible manganese. Apparently, on these soils there is no straight relationship between manganese uptake by pasture grass and reducible soil manganese. This is in accordance with de Groot (1957) who states that on clay and peaty clay soils pH is a better indication for pasture manganese than either exchangeable or reducible soil manganese.

The question may arise whether the pasture manganese contents encountered on the control plots in the present experiments are in the deficient or sufficient range for satisfactory growth and reproduction of dairy cattle. According to Bosch et al. (1965) 50 p.p.m. of manganese is fully adequate under Dutch conditions. Prolonged periods during which the pasture manganese content falls below this level are considered rare. Whatever the view on fertilizing pasture with manganese may be, it is clear that the manganese frit used in the above experiments did not affect manganese content of the sward, whereas manganese sulphate only had a temporary effect.

Table 3 gives the results of experiment IB 454. Statistical analysis showed that the effects of treatment on seed yield and percentage of marsh spot were significant at the $5 \%$ level; there was no significant effect on straw yield. The Duncan test (Table 3) revealed that a combination of soil and foliar applied manganese sulphate (treatment $c$ ) was significantly better with respect to seed yield than either spraying ( $d$ and $e$ ) alone or application of frit $\mathrm{HZ} 1$. However, due to the large experimental error $(c)$ did not differ significantly from the control. Although the manganese sulphate treatments $(b, c, d, e)$ did not differ significantly with respect to marsh spot incidence,

Table 2 Effect of different manganese fertilizers on pasture manganese (p.p.m. on dry matter) as determined in different cuts in experiment $Z 2160$; each figure represents the mean of four plots

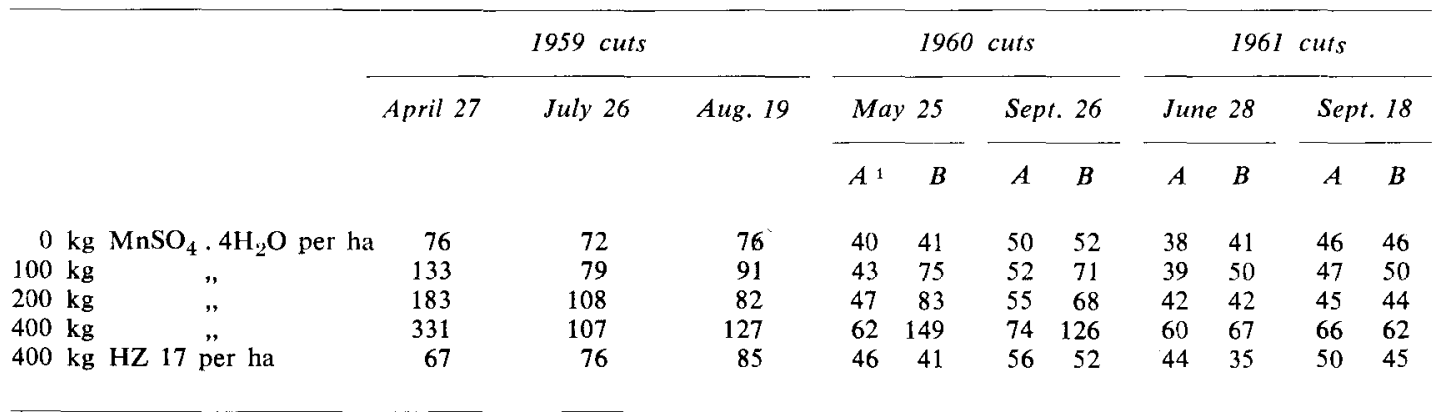

\footnotetext{
1 $\mathrm{A}=$ application of fertilizers in 1959 only; $\mathrm{B}=$ application of fertilizers in 1959 and 1960
} 
Table 3 Effect of different manganese fertilizers and different methods of application on straw and seed yield (in $100 \mathrm{~kg} / \mathrm{ha}$ ) and percentage of marsh spot of peas (field experiment IB 454); each figure represents the mean of six replications

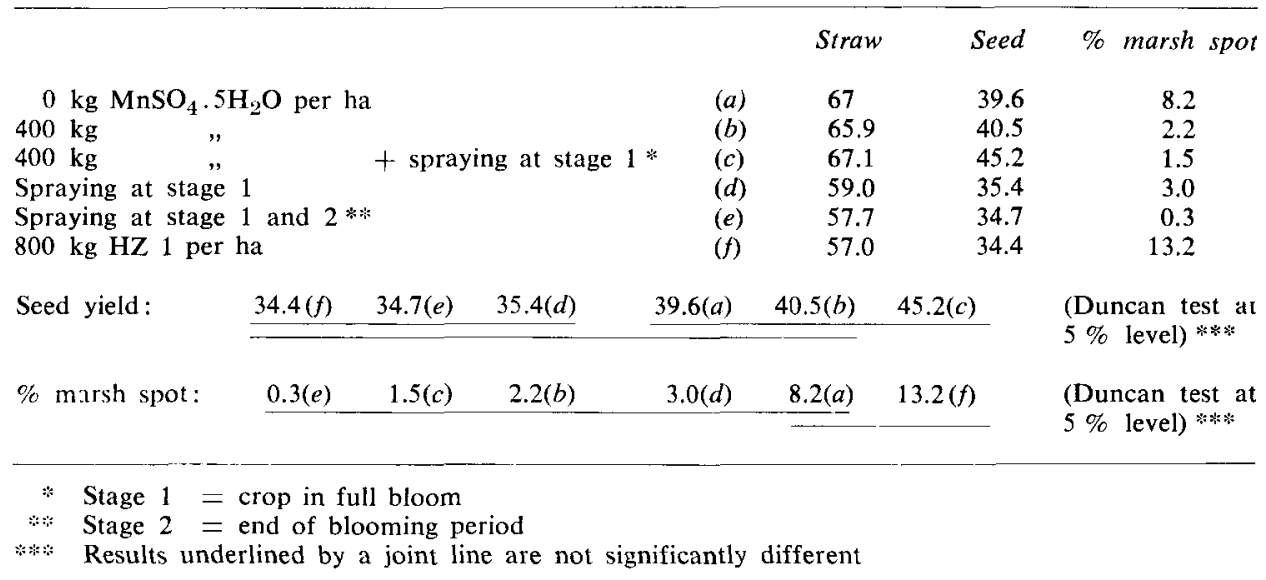

the lowest percentage of affected seeds occurred when the crop was sprayed twice (e). In general, the best control of marsh spot is obtained by a foliar spray in the middle and at the end of the blooming period, as is clearly pointed out in another paper (Henkens and Jongman, 1965). An adequate supply of manganese during this critical period is essential to control marsh spot. The results of other experiments (not yet published) indicate that soil applied manganese sulphate does not decrease marsh spot. Application of frit $\mathrm{HZ} 1$ not only resulted in the lowest seed and straw yield, but also in the highest percentage of affected seeds, which was higher than that of each manganese sulphate treatment and the control, the difference with the latter not being significant though. The leaves of plants supplied with $\mathrm{HZ} 1$ showed a whitish-yellow discoloration which partially disappeared later in the season. This is probably caused by a toxic effect of the manganese carrier and not by manganese toxicity, as orach plants (Atriplex hortense) occurring in the frit plots showed symptoms of manganese deficiency.

Results of experiment IB 656 are shown in Table 4. Observation during the growing season showed that both soil application of various manganese fertilizers and a foliar spray of manganese sulphate had a favourable effect on crop growth. There was not much difference between soil and foliar applied manganese sulphate and frit $\mathrm{HZ} 17$ in this respect, but the plants receiving the lower quantities of $\mathrm{HZ} 1$ were somewhat less vigorous. At first, all treatments considerably reduced manganese deficiency incidence as is shown by the survey on 5th September. Later on (12th October), the number of manganese deficient plants had greatly increased on all plots, the relative increase being largest on the treated ones however. Apparently, soil application of manganese fertilizers did not provide a steady supply of available manganese during the entire growing period. Spraying also gave only a temporary control of manganese deficiency, the symptoms occurring again in the leaves formed after this treatment. This is ascribed to the fact that manganese is not easily translocated from mature to young leaves (Henkens and Jongman, 1965).

All soil applied manganese fertilizers increased yield of beet roots at the $1 \%$ and 
EVALUATION OF GLASSY FRITS AS MICRONUTRIENT FERTILIZERS. II.

Table 4 Effect of different manganese fertilizers and different methods of application on yield of beet roots, foliage weight and sugar production (in $100 \mathrm{~kg} / \mathrm{ha}$ ), incidence of manganese deficiency and leaf manganese content (in p.p.m. on dry matter) of sugar beets, and on reducible soil manganese (in p.p.m.); each figure represents the mean of four plots (experiment $I B$ 656)

\begin{tabular}{|c|c|c|c|c|c|c|c|}
\hline & \multirow[t]{2}{*}{ Beets } & \multirow[t]{2}{*}{ Foliage } & \multirow[t]{2}{*}{ Sugar } & \multicolumn{2}{|c|}{ Mn def. plants } & \multirow{2}{*}{$\begin{array}{c}\text { Leaf } M n \\
10 / 7\end{array}$} & \multirow{2}{*}{$\begin{array}{c}\text { Red. soil } \\
M n\end{array}$} \\
\hline & & & & $5 / 9$ & $12 / 10$ & & \\
\hline $0 \mathrm{~kg} \mathrm{MnSO}_{4} \cdot 5 \mathrm{H}_{2} \mathrm{O}$ per ha* & 574.4 & 310.3 & 82.9 & 11.6 & 25.8 & 19.5 & 34.9 \\
\hline $100 \mathrm{~kg}$ & 640.3 & 321.3 & 93.4 & 3.1 & 21.3 & 18.5 & 39.8 \\
\hline $200 \mathrm{~kg}$ & 629.3 & 352.3 & 91.9 & 3.4 & 20.3 & 20.0 & 49.8 \\
\hline $400 \mathrm{~kg} \quad "$, & 649.8 & 368.3 & 95.5 & 2.7 & 14.5 & 26.3 & 53.0 \\
\hline $178.6 \mathrm{~kg} \mathrm{HZ} 1$ per ha & 616.0 & 332.3 & 90.1 & 4.5 & 18.8 & 18.8 & 48.0 \\
\hline $357.1 \mathrm{~kg}$ & 645.5 & 343.8 & 92.7 & 3.5 & 17.4 & 23.3 & 46.5 \\
\hline $714.3 \mathrm{~kg}$ & 631.5 & 313.5 & 94.1 & 1.0 & 14.8 & 27.5 & 60.8 \\
\hline $85.8 \mathrm{~kg} \mathrm{HZ} 17$ per ha & 652.5 & 355.5 & 95.4 & 4.2 & 22.4 & 19.3 & 39.0 \\
\hline $171.4 \mathrm{~kg}$ & 628.3 & 344.8 & 90.2 & 2.9 & 18.2 & 20.3 & 43.0 \\
\hline $342.9 \mathrm{~kg}$ & 619.5 & 308.8 & 89.1 & 2.4 & 12.1 & 26.5 & 55.3 \\
\hline Spraying on $5 / 6$ and $3 / 7$ & 605.8 & 317.5 & 88.9 & 1.2 & 16.8 & - & 30.5 \\
\hline
\end{tabular}

Duncan test at $5 \%$ level **

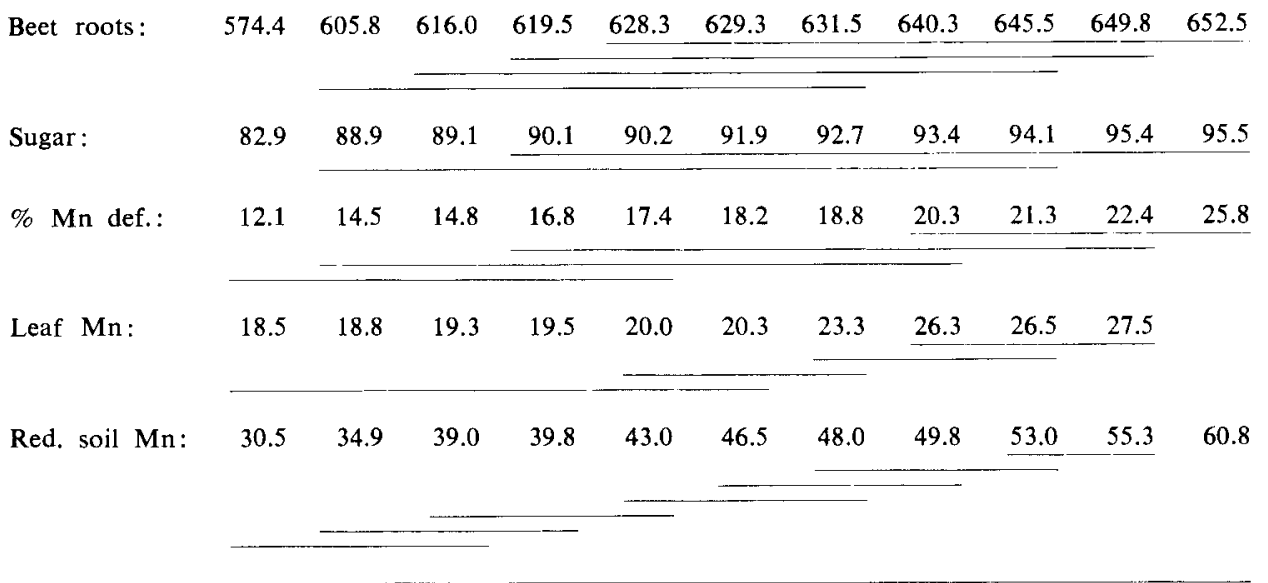

* Means of eight plots

$*$ Results underlined by a joint line are not significantly different

foliar applied manganese sulphate at the $5 \%$ level of significance. With increasing levels of manganese there was no accompanying significant increase in yield, a maximum response already being obtained at the lowest level of manganese supplied, i.e. $18-28 \mathrm{~kg}$ of manganese per hectare. Spraying proved slightly less effective than soil application, but there was found to be no significant difference between manganese frits and manganese sulphate in this respect. Sugar production closely paralleled beet yield, all treatments resulting in a significant increase at $5 \%$. Spraying was significantly less effective than either $400 \mathrm{~kg}$ of manganese sulphate or $85.8 \mathrm{~kg}$ of manganese frit $\mathrm{HZ} \mathrm{17}$, but none of the other differences was significant (Duncan test). Neither treatment had a significant influence on foliage weight. 


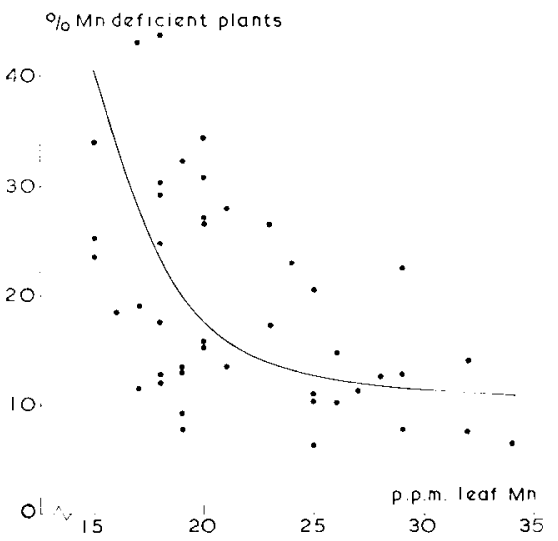

Fig. I Relationship between leaf manganese content and percentage of manganese deficient sugar beet plants (field experiment IB 656).

All manganese fertilizers highly significantly increased leaf manganese at the highest levels of supply, the lower applications not being effective. There was no significant difference between the various manganese products in this respect. Leaf analytical data for the sprayed plots were obscured by contamination and are, therefore, not recorded in Table 4.

Reducible soil manganese highly significantly increased with increasing quantities of soil applied manganese fertilizers, but the differences between control and first level of manganese sulphate and manganese frit $\mathrm{HZ} \mathrm{17,} \mathrm{respectively,} \mathrm{were} \mathrm{not} \mathrm{significant.}$ No consistent differences occurred between manganese sulphate and manganese frits as regards their effect on reducible soil manganese. At the lowest and highest level of manganese supply frit $\mathrm{HZ} 1$ gave a greater increase than either manganese sulphate

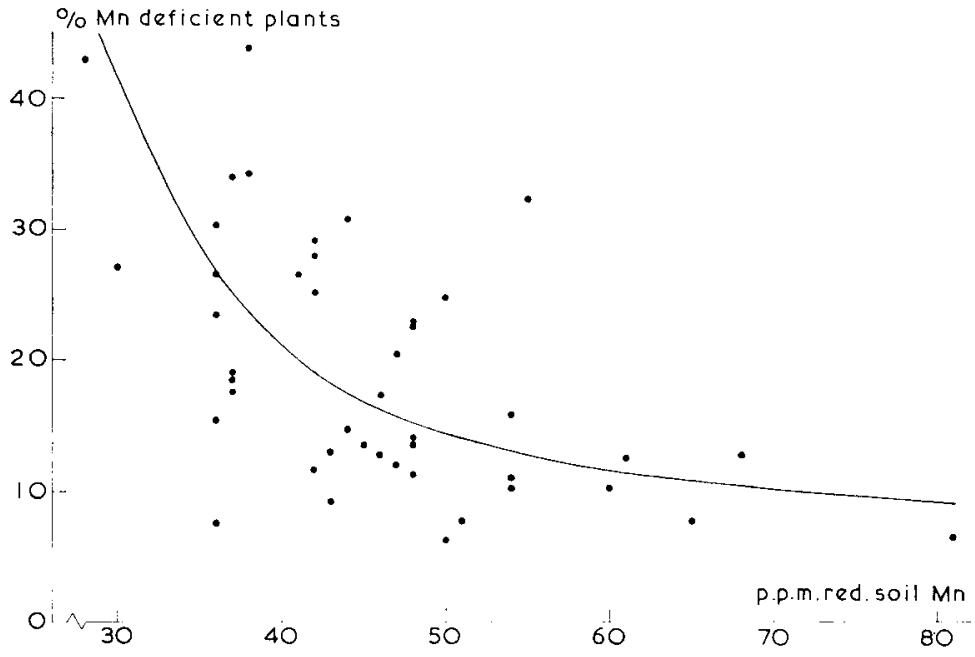

Fig. 2 Relationship between reducible manganese content of the soil and percentage of manganese deficient sugar beet plants (field experiment IB 656). 
or frit $\mathrm{HZ} \mathrm{17,} \mathrm{whereas} \mathrm{at} \mathrm{the} \mathrm{intermediate} \mathrm{level} \mathrm{there} \mathrm{was} \mathrm{no} \mathrm{difference} \mathrm{between}$ frit $\mathrm{HZ} 1$ and manganese sulphate, the latter producing a greater increase than frit $\mathrm{HZ} 17$, however. As has been pointed out on p. 23, the quantities of manganese supplied per hectare are somewhat different for the various manganese fertilizers which may partly account for these differences.

The relationships between leaf manganese, reducible soil manganese and incidence of manganese deficiency (on 12th October) are illustrated in Fig. 1, 2 and 3. Leaf manganese is negatively related to the percentage of manganese deficient plants (Fig. 1). It can be postulated that the critical level below which deficiency symptoms occur, lies above 35 p.p.m. Mn, which is somewhat higher than the value mentioned by Finck and de Groot (1965). Reducible soil manganese is also negatively related to the percentage of manganese deficient plants (Fig. 2); there is a considerable amount of deviation from the average curve however. In other words, with equal levels of reducible manganese in various plots the number of affected plants may be rather different. This is in accordance with Finck and de Groot (1965) who point out that on some polder soils in the Netherlands the level of reducible manganese does not provide a definite criterion for the occurrence of manganese deficiency, other factors (calcium carbonate and organic matter content) also being involved. Fig. 3 shows that there is a fairly good relationship between leaf and reducible soil manganese. Beet yield was not found to be closely related to manganese deficiency incidence (on 12th October).

In the following crop, oats, soil treatment in the preceding year had no significant effect on straw and grain yield, average grain weight and leaf manganese content (Table 5). It is true that the higher applications of manganese sulphate and frits had a significant residual effect on reducible soil manganese but, as compared with the previous year (Table 4), the levels had dropped considerably. The differences between the various products had leveled off as compared with the preceding year. There was

35 : p.p.m. leaf $\mathrm{Mn}$

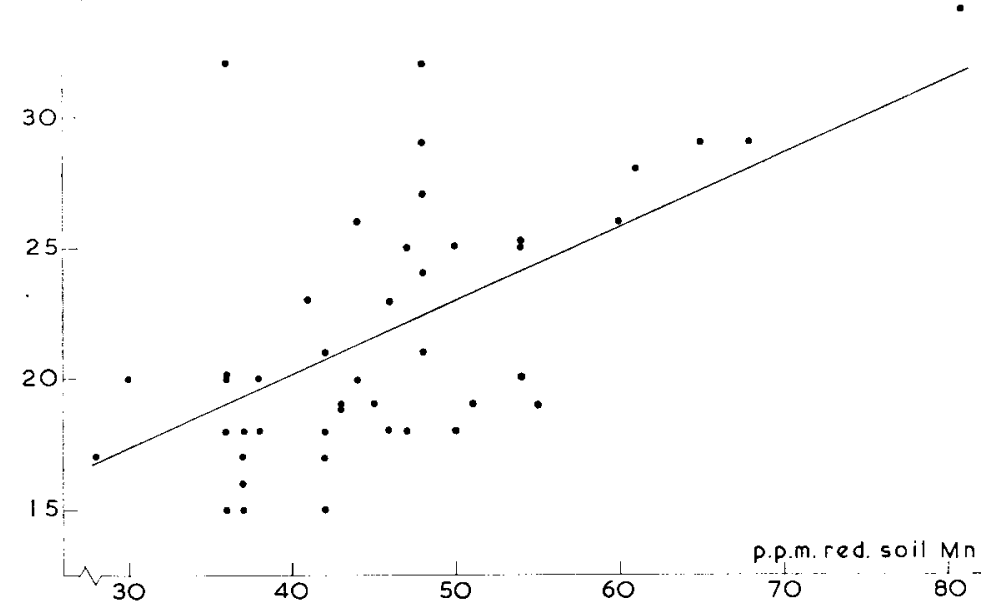

Fig. 3 Relationship between leaf manganese (sugar beets) and reducible soil manganese content (field experiment IB 656). 
Table 5 Effect of different soil applied manganese fertilizers (one year before cropping) and of foliar applied manganese sulphate on straw and grain yield (in $100 \mathrm{~kg} / \mathrm{ha}$ ), average grain weight (1000 grains) and leaf manganese content of oats (in p.p.m. on dry matter), and on reducible soil manganese (in p.p.m.)

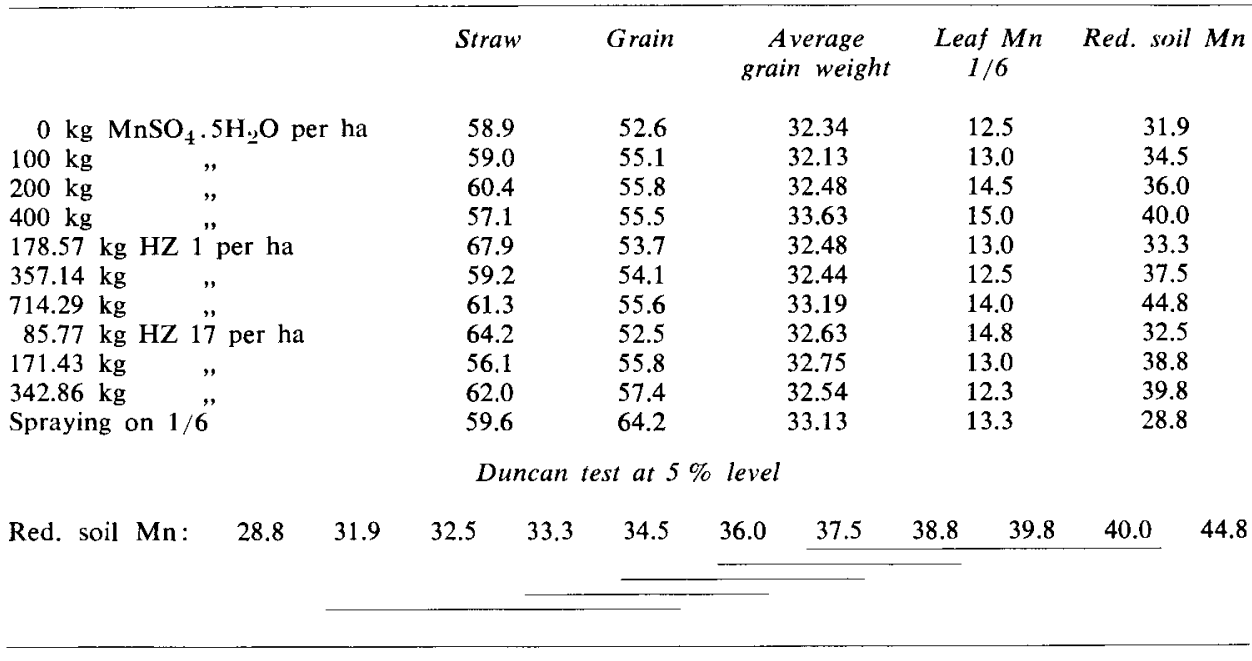

a patchy occurrence of grey speck in both the control and the manganese sulphate and frit treated plots. Apparently, application of manganese sulphate or manganese frit to the soil one year prior to cropping could not effectively control grey speck. Spraying, however, did completely control the deficiency disease and also increased grain yield significantly.

\section{References}

Bosch, S., Grift, J. van der and Hartmans, J., 1965. Mangaanbehoefte bij opgroeiende en lacterende runderen. Versl. Landbouwk. Onderz. $666: 41 \mathrm{pp}$.

Finck, A. and Groot, A. J. de, 1965. Manganhaushalt Schleswig-Holsteinischer und Niederländischer Marsböden. Landw. Forsch. Sonderheft, 19:3-11.

Groot, A. J. de, 1957. Mangaangebrek in Nederland. Landbouwk. Tijdschr., 69 : 564-574.

Henkens, Ch. H., 1958. The trace element manganese; the state of research in The Netherlands. Neth. J. Agric. Sci., 6: 191-203.

Henkens, Ch. H., 1959. Bestrijding van mangaangebrek door bemesting van de grond. Landbouwk. Tijdschr. $71: 7-21$.

Henkens, Ch. H., 1962. Manganmangel und dessen Beseitigung. Landw. Forsch. Sonderheft, 16 : $66-71$.

Henkens, Ch. H. and Jongman, E., 1965. The movement of manganese in the plant and the practical consequences. Neth. J. Agric. Sci., 13: 392-407.

Henkens, Ch. H. and Smilde, K. W., 1966. Evaluation of glassy frits as micronutrient fertilizers. I. Copper and molybdenum frits. Neth. J. Agric. Sci., 14 : 165-177.

Leeper, G. W., 1947. The forms and reactions of manganese in the soil. Soil Sci., 63: 79-94.

Middelburg, H. A. and Baren, H. van, 1965. Bemesting met mangaan in fritvorm. Landbouwk. Tijdschr., $77: 123-134$.

Oosting, M., 1964. Die Freisetzung von Spurenelementen aus FTE (fritted trace elements). Z. Pflanzenernähr. Düng. Bodenk., 106 : 206-218. 